ARTIGOS

\title{
DOCÊNCIA NAS FRONTEIRAS: QUILOMBO, RAÇA E GÊNERO
}

Shirley Aparecida de MIRANDA Universidade Federal de Minas Gerais (UFMG) Belo Horizonte, Minas Gerais - Brasil

Mirandashirley48@gmail.com

ORCID: https://orcid.org/0000-0001-8312-2262

Jairza Fernandes Rocha da SILVA Universidade Federal de Minas Gerais (UFMG) Alfenas, Minas Gerais - Brasil professorajairza@gmail.com ORCID: https://orcid.org/0000-0001-6858-8427

\begin{abstract}
Resumo: Os quilombos no Brasil consistem no mais evidente mecanismo de enfrentamento ao sistema escravista, emblema da resistência coletiva que constitui a diáspora africana. Em 2012 foram publicadas as diretrizes curriculares nacionais para a educação escolar quilombola. As recomendações e desafios dessa modalidade de educação dirigem-se às professoras. Poderíamos falar então em uma docência quilombola? Esse artigo discute essa indagação a partir das narrativas de quatro professoras que se reconhecem quilombolas, se autodeclaram negras e atuam em escolas situadas nos territórios onde vivem. Seguimos nas trilhas das narrativas para evidenciar quem são e como se formaram docentes quilombolas e que deslocamentos produzem para a relação entre gênero e docência. O artigo está organizado em cinco tópicos. Após a introdução, discutimos os percalços da formação docente das professoras entrevistadas. No terceiro tópico refletimos sobre a relação gênero e raça e as desestabilizações que propõem a uma análise da profissão docente. No tópico seguinte, situamos as fronteiras em que constroem a docência quilombola e palavras finais.
\end{abstract}

Palavras-chave: Docência, quilombo, raça, gênero.

\section{TEACHING AT THE BORDERS: QUILOMBO, RACE AND GENDER}

\begin{abstract}
Quilombos in Brazil are the most evident mechanism for confronting the slave system, an emblem of the collective resistance that constitutes the African diaspora. In 2012, the national curriculum guidelines for quilombola school education were published. The recommendations and challenges are highlighted for teachers. Could we then talk about quilombola teaching? This article discusses this question based on the
\end{abstract}




\section{autêntica}

DOI https://doi.org/10.31639/rbpfp.v12i24.348

narratives of four teachers who recognize themselves as quilombolas, call themselves black and work in schools located in the territories where they live. We followed the trails of the narratives to show who they are and how quilombola teachers were trained and what displacements they produce for the relationship between gender and teaching. The article is organized into five topics. After the introduction, we discussed the pitfalls of teacher training of the interviewed teachers. In the third topic, we reflect on the gender and race relationship and the destabilizations that propose an analysis of the teaching profession. In the next topic, we situate the borders on which quilombola teaching is built and final words.

Keywords: Teaching. quilombo. race. gender

\section{ENSEÑANZA EN LAS FRONTERAS: PALENQUES, RAZA Y GÉNERO}

Resumen: Los palenques en Brasil son el mecanismo más evidente para enfrentar el sistema esclavista, un emblema de la resistencia colectiva que constituye la diáspora africana. En 2012, se publicaron las pautas curriculares nacionales para la educación escolar de quilombola. Se destacan las recomendaciones y desafíos para la implementación de este tipo de educación para los maestros. ¿Podríamos hablar sobre la enseñanza de la palenquera? Este artículo discute esta pregunta basada en las narraciones de cuatro maestras que se reconocen a sí mismos como palenqueras, se autodenominan negras y trabajan en escuelas ubicadas en los territorios donde viven. Seguimos los rastros de las narraciones para mostrar quiénes son y cómo se capacitó a los maestros de palenqueras y qué desplazamientos producen para la relación entre género y enseñanza. El artículo está organizado en cinco temas. Después de la introducción, discutimos las trampas de la capacitación docente de los maestras entrevistadas. En el tercer tema, reflexionamos sobre la relación de género y raza y las desestabilizaciones que proponen un análisis de la profesión docente. En el siguiente tema, situamos las fronteras sobre las cuales se construye la enseñanza palenquera y las palabras finales.

Palabras-clave: Enseñanza. quilombo. raza. género 


\section{autêntica}

DOI https://doi.org/10.31639/rbpfp.v12i24.348

\section{Introdução}

Os quilombos no Brasil consistem no mais evidente mecanismo de enfrentamento ao sistema escravista, emblema da resistência coletiva que constitui a diáspora africana. Contudo, a acepção criminal atribuída aos quilombos pela inscrição colonial ${ }^{1}$ atravessou mais de dois séculos. Como resultado, os quilombos estiveram ausentes no aparato jurídico no que se refere ao reconhecimento de direitos e ativos no aparato midiático, literatura, livros didáticos como um fenômeno do passado escravista. No âmbito da produção cientifica, quilombo destaca-se como conceito contestado e disputado pela "insurgência das comunidades negras contemporâneas, rurais e urbanas, que resistiram aos artifícios de apagamento material e simbólico a que foram submetidas" (Miranda, 2018, 195).

As comunidades negras rurais, terras de preto, ou agrupamentos negros rurais, emergiram vigorosamente em 1988, ano do Centenário da Abolição e da promulgação da Constituição Federal do Brasil conhecida por "Constituição Cidadã". Naquele contexto de lutas por democratização do Estado, emergência de direitos e igualdade racial, o espectro conceitual dos quilombos foi reconfigurado passando a incluir as "comunidades negras, constituídas a partir de diversos marcos fundadores, sejam heranças de antigos senhores, compra de terras por pessoas ou grupos familiares, ocupação de terras abandonadas por senhores de escravos etc" (Santana, 2015, p.35).

A culminância desse reconhecimento em âmbito jurídico imprimiu-se na Constituição Federal do Brasil de 1988, em seu Art. 68, que reconhece a propriedade definitiva das terras ocupadas pelos "remanescentes de comunidades de quilombos" e no Art. 216, que insere os quilombos no conjunto do patrimônio cultural brasileiro, caracterizados como "portadores de referência à identidade, à ação, à memória dos diferentes grupos formadores da sociedade brasileira". O mesmo artigo determina o tombamento de "todos os documentos e sítios detentores de reminiscências históricas dos antigos quilombos".

Em 2012 foram publicadas as diretrizes curriculares nacionais para a educação escolar quilombola², uma medida tardia para efetividade do reconhecimento dos quilombos como "patrimônio nacional" conforme definido no marco jurídico nacional. Essa modalidade de educação, embora recente, está sendo composta com a estrutura das escolas existentes nos quilombos e das escolas que, mesmo fora dos territórios ${ }^{3}$, atendam aos estudantes quilombolas. As recomendações, assim como os tensões e os desafios as da implantação da educação escolar quilombola dirigem-se principalmente, às professoras dessas escolas. A determinação de que a educação escolar quilombola "deverá ser conduzida, preferencialmente, por professores pertencentes às comunidades quilombolas" (Resolução CNE/CBE/ n 8, 2012, Art. 48), assim como a ênfase na formação inicial e continuada de professores são indícios da importância atribuída à docência na implantação da modalidade.

1 Conforme os Autos do Conselho Ultramarino, de 1740, “toda habitação de negros fugidos, que passem de cinco, em parte despovoada, ainda que não tenham ranchos levantados e nem se achem pilões neles" (Moura, 1981, p. 25). Essa referência recuperada por Moura (1981) foi retomada também em Almeida (2002), Schmitti, O’Dwyer (2002), Turatti e Carvalho (2002), Arruti (2005, 2008).

2 A educação escolar quilombola foi instituida como uma modalidade pela Resolução CNE/CEB n ${ }^{\circ} 4 / 2010$, que definiu Diretrizes Curriculares Nacionais Gerais para a Educação Básica, com base no Parecer CNE/CEB nº 7/2010. Em 2012, a Resolução CNE/CEB nº 08 definiu Diretrizes Curriculares Nacionais para a Educação Escolar Quilombola na Educação Básica, com amparo no Parecer CNE/CEB nº 16/2012. O extenso arcabouço jurídico que embasou essa medida pode ser consultado ao longo das duas páginas de abertura da Resolução CNE/CEB nº 08/2012.

3 Nos limites desse artigo optamos por não aprofundar a discussão sobre a noção de território. Entretanto, sinalizamos que apoiamo-nos na concepção de território usado no exercício da vida, espaço apropriado, territorializado, concreta ou abstratamente. Remetemo-nos a Milton Santos (2000, p. 96) para quem o "território é a base do trabalho, da resistência, das trocas materiais e espirituais e da vida sobre os quais ele influi". Portanto, não nos referimos ao território juridicamente demarcado, mas sim, ao território que sustenta o pertencimento de uma comunidade quilombola. 


\section{autêntica}

Poderíamos falar então em uma docência quilombola? Esse artigo discute indagação a partir dos resultados de uma pesquisa de mestrado, de caráter qualitativo. Foram entrevistadas cinco professoras que atuam em escolas situadas em territórios quilombolas e que participaram do primeiro curso de aperfeiçoamento para Formação de Professores/as da Educação Básica nas Comunidades Remanescentes de Quilombo (Kizomba) ${ }^{4}$. Nesse artigo, destacamos as narrativas de quatro professoras que se reconhecem quilombolas, se autodeclaram negras e atuam em escolas situadas nos territórios onde vivem. Seguimos nas trilhas das narrativas dessas quatro professoras para evidenciar quem são e como se formaram docentes quilombolas.

\section{Percalços da formação inicial de professoras quilombola}

E praticamente parece que eu venho arrancando, abrindo caminho com as próprias unhas, né! Porque nós, mulheres negras, nós, pessoas negras, ainda somos povos vindos de família humilde. (Entrevista narrativa, Professora Sirlene ${ }^{5}$ ).

As conquistas obtidas pela população quilombola em sua intensa luta por reconhecimento ainda são insuficientes para reparar a humanidade confiscada pelo passado de violência colonial. Em uma sociedade na qual o racismo é estrutural e que mantém relações de opressão com base no sistema escravista, uma das principais dificuldades enfrentadas pela população quilombola segue sendo o direito à terra.

$\mathrm{Na}$ atual conjuntura brasileira os conflitos pelo direito de posse coletiva das terras ocupadas pelas comunidades quilombolas estão se acirrando. Conforme assinala Jairza Silva (2018, p. 35), os territórios quilombolas coincidem com áreas de grande interesse econômico, que ainda conservam disputados recursos em sua biodiversidade.

De acordo com os dados divulgados pela Fundação Cultural Palmares, em novembro de 2017 o Brasil possuía cerca de 3.238 comunidades quilombolas certificadas ${ }^{6}$, das quais somente 220 possuíam o título de posse.

Conforme os dados do Guia de Políticas Públicas para as Comunidades Quilombolas - Programa Brasil Quilombola, elaborado pela Secretaria de Políticas de Promoção da Igualdade Racial da Presidência da República (SEPPIR), até 2013 constavam cerca de 214 mil famílias e 1,17 milhões de habitantes nas comunidades quilombolas espraiadas por todo o território nacional. Em relação à escolarização da população quilombola, os dados indicam que $24,81 \%$, do total da população quilombola no país, não sabe ler. Em Minas Gerais observa-se o mesmo padrão. O Diagnóstico Institucional da Educação Escolar Quilombola, elaborado pela Secretaria Estadual de Educação em 2015, revelou que a taxa de analfabetismo dessa população era de 25\%, "quase o triplo do valor encontrado no estado de Minas Gerais como um todo (Minas Gerais, 2015, p. 15-16).

\footnotetext{
4 Kizomba foi o primeiro Curso de Formação de Professores/as da Educação Básica nas Comunidades Remanescentes de Quilombo de Minas Gerais, em nível de aperfeiçoamento na modalidade presencial. O curso foi desenvolvido pelo Programa Ações Afirmativas na UFMG, como parte do Programa de Ações Afirmativas para a População Negra nas Instituições Federais e Estaduais de Educação Superior (Uniafro) do Ministério da Educação. O Kizomba ocorreu de setembro de 2014 a março de 2015 atendendo 137 professores em dois pólos de formação nas regiões de maior concentração de comunidades quilombolas em Minas Gerais: região Norte, no pólo de Januária e Vale do Jequitinhonha, no pólo de Berilo. Kizomba tem origem no kimbundu, uma das línguas faladas de Angola, e significa encontro, confraternização. No Brasil também se refere à festa do povo, conforme o nome das danças dos negros(as) que resistiram ao processo de escravização.

5 Ao consentir em participar da pesquisa as professoras optaram por não utilizar nomes fictícios e manter os nomes próprios de registro civil.

6 Até 2017, último ano em que se registra a aplicação desse procedimento, a certificação era conferida pela Fundação Cultural Palmares conforme definido pelo Decreto 4288. A certificação era um critério para acesso das comunidades quilombolas às políticas públicas e programas específicos, os quais foram interrompidos a partir de 2019. A emissão dos títulos de posse ocorreria numa segunda fase, a publicação do ato de reconhecimento da comunidade como remanescente de quilombo e a outorga da titulação pelo Instituto Nacional de Colonização e Reforma Agrária (INCRA).
} 


\section{autêntica}

A esse dado alarmante adicionam-se as barreiras de acesso aos níveis mais elevados de educação superior, como a inexistência de escolas nos territórios, longas distâncias para acessá-las fora do território e descontinuidade no atendimento educacional. A quem ultrapassar as barreiras do acesso, resta uma educação escolar cuja tendência predominante é obstaculizar ou negligenciar conhecimentos que proporcionariam aos quilombolas estabelecerem uma relação com o seu entorno baseada na autonomia e no reconhecimento (Miranda 2018, p. 201).

É nesse contexto de disputas que situamos uma docência quilombola. Considerando que escolarização das pessoas quilombolas ocorre numa dinâmica de negações e exclusões produziu, entre outros resultados, a ausência de professoras para atuarem na própria comunidade. Desse modo, a orientação de que a educação escolar quilombola deva ser conduzida pelas professoras das comunidades (Resolução CNE/CEB n 8/2012), ao mesmo tempo em que reforça o caráter territorializado dessa modalidade de educação, assinala desafios que a política educacional tem a superar.

Na pesquisa que fundamenta esse artigo nos encontramos com narrativas que explicitam as restrições combatidas por professoras quilombolas em sua formação. Entre as cinco pesquisadas, apenas uma cursou todo o ensino fundamental em sua comunidade. Até concluírem o ensino médio, todas tiveram que realizar o movimento pendular entre o quilombo e a cidade, diariamente, enfrentando longas distâncias sem contar transporte regular, ou residindo temporariamente e de modo precário na sede do município. Viver longe do quilombo, na ausência da família e com arranjos de moradia provisória caracteriza as circunstâncias da formação escolar dessas professoras. Esses percalços produziram hiatos entre a conclusão do ensino médio e a inserção no ensino superior. Primeiro, elas tiveram que pavimentar o terreno que acabaria por conduzi-las aos cursos na modalidade de Educação a Distância (EaD) devido à impossibilidade de acessar as universidades públicas, localizadas nos grandes centros urbanos ou em regiões circunvizinhas.

Ao repertório adquirido por essas professoras na formação inicial, que inclui de modo decisivo o enfrentamento das barreiras materiais, vieram a somar-se os dilemas do pertencimento quilombola. Conforme constata Miranda (2018, p. 202), foi a partir de 2010, após a configuração da educação quilombola como modalidade de ensino, que a escola "passou a figurar como uma instância a ser disputada na consolidação de uma identidade quilombola". As professoras que atuam em escolas quilombolas foram instadas a se posicionar acerca desse pertencimento.

Com efeito, a identidade quilombola é negociada, forjada no decorrer de processos de invisibilidade ativamente produzida e de visibilidade insurgente. Uma análise das pesquisas sobre quilombos e educação (Miranda, 2018 , 199) revela que a maioria das produções orienta-se segundo a premissa de que as identidades não são fixas, tomando por referência preponderante os trabalhos de Stuart Hall (2006a, 2006b) que reposiciona esse conceito. A identidade opera de forma estratégica e contingente. Com base nessa referência a identidade quilombola é concebida em meio aos dilemas de pertencimento a um determinado território material e simbólico inserido em disputas econômicas e atravessada por representações sociais negociadas ou contestadas. "Uma identidade nem sempre reconhecida e que, portanto, é conquistada, agenciada e certamente disputada" (Miranda, 2018, 199). Enfim, a identidade quilombola é política, ou seja, estabelecida por uma prática discursiva que posiciona e reconfigura as fronteiras do pertencimento. As professoras com quem dialogamos elaboram esse pertencimento na confluência com a elaboração da identidade negra:

Porque realmente ainda existe muito racismo e o preconceito não acabou, ele só mudou de nome. Ele não acabou para muita gente. [...] [Entender] O porquê dos nossos cabelos duros. O porquê da nossa cor da pele. Porque a nossa cor da pele e os nossos cabelos duros não vão interferir na nossa capacidade. Que isso não diminui em nada a gente. Se auto respeitar. Se os outros querem 


\section{autêntica}

respeito, nós também. [...] foi em 2006, que começaram a aparecer as comunidades quilombolas lá na minha região, onde a Palmares entrou e a nossa comunidade e várias outras vizinhas foram reconhecidas como quilombola. Aí, mais outra discriminação preta, negra, mulher, pobre e quilombola. Aumentou mais uma. Mas nem por isso eu vou baixar a minha cabeça. Isso me deu mais força, mais coragem. (Professora Dermita, Entrevista Narrativa, 2017).

A afirmação de que a identidade é política não rejeita o processo de subjetivação que conforma a pertença identitária. Conforme contatamos, é pela elaboração da pertença étnico-racial por vezes contraditória e conflituosa que se afirmam as professoras negras quilombolas. Pudemos perceber também nas narrativas das docentes, que tais confrontos são muito recentes para elas. Diríamos que essas docentes vão se posicionando à medida em que elaboram as margens do pertencimento, de modo que "definir-se é um status importante de fortalecimento e demarca possibilidades de transcendência da norma colonizadora" (RIBEIRO, 2017, p. 44).

Então, é possível considerar que esse pertencimento docente-negra-quilombola é elaborado por essas professoras numa base comum na qual entram em jogo as margens do reconhecimento jurídico - nas quais se inscrevem as políticas públicas de ação afirmativa e se inclui a formação continuada -, o território quilombola e afirmação racial. A partir dessa confluência indagamos um aspecto constitutivo da docência conforme demonstram as pesquisas em educação: a feminilização do magistério, ou seja, o gênero na docência.

\section{Mulheres negras e gênero na docência quilombola}

O pessoal fala de profissão de mulher. O que eu falo com elas? Que lugar de mulher é no fogão? Eu falo que não, lugar de mulher é onde que ela quiser. E eu falo sempre pras minhas jovens, não só na minha comunidade como na própria escola.

(Professora Dermita Entrevista Narrativa, 2017)

Os debates sobre identidade docente conferem centralidade ao processo de feminização do magistério. Sá e Rosa (2004), em sua revisão bibliográfica sobre a história da feminização do magistério, mencionam que no campo da história da educação, uma parte significativa das pesquisas buscava compreender esse processo elucidando as razões para o crescimento do número de mulheres dentro dessa categoria profissional e as alterações pelas quais passou esse ofício.

A feminização do magistério ${ }^{7}$ é considerada como um fenômeno que se deu em nível mundial, no final do século $\mathrm{XIX}$ e ao longo do século $\mathrm{XX}$, regulado por mudanças nas relações patriarcais e econômicas. De acordo com Chamon (2005), o impulso da entronização das mulheres na profissão docente assentou-se no papel moral que poderiam desenvolver junto à massa trabalhadora que passou a ser regida por uma nova racionalidade organizacional do processo de trabalho. A presença feminina começou então a ser efetivada, a partir do final do século XIX, e seguiu nessa tendência, ao longo do século XX, processo que ocorreu também no Brasil com as suas devidas particularidades. Às mulheres abriu-se a possibilidade de obterem instrução nas escolas normais e ingressarem na carreira do magistério, função que antes era destinada aos homens.

Todavia, a presença das mulheres nessa carreira profissional coincide com a proletarização da docência nos níveis básicos da educação, ou seja, a desvalorização do status da profissão, com consequências econômicas.

7 Para maior aprofundamento sobre o processo de feminização do magistério: ALMEIDA (1998), APPLE (1995), ARAÚJO (1990), CASTANHA (2015), CHAMON (2005), FARIA FILHO e MACEDO (2004), HAHNER (2011), NÓVOA (1989), SÁ e ROSA (2004), dentre outras/os. 


\section{autêntica}

DOI https://doi.org/10.31639/rbpfp.v12i24.348

Além disso, a esse nível de ensino é associada a função doméstica do cuidado e formação moral, as quais funcionam em continuidade com a ideologia da docilidade feminina.

Apesar de restrita, a presença de mulheres negras no magistério no final do século XIX foi detectada nos trabalhos desenvolvidos por Müller $(2006$, 2016). Segundo a autora, no final da Primeira República, se iniciou um processo de "branqueamento" do magistério, que acompanhava as tendências políticas do período e desse modo, essa presença restrita passou a inexistente desde os cursos de formação, com raras exceções.

Considerando essa assimetria entre mulheres negras e mulheres brancas, mesmo num contexto de disparidade entre homens e mulheres, refletir sobre a feminilização do magistério exige interrogar a quem o substantivo mulheres representa. Esse questionamento emergiu vigorosamente na obra de feministas negras, como Angela Davis (1981), Alice Walker (1983), e bell hooks (1981), que à época denunciavam que a teoria não abrangia as vivências das mulheres negras.

Mulher era sinônimo de mulher branca [...] o imperialismo racial dos brancos apoiou o costume de acadêmicos em usar o termo "mulheres" mesmo que eles se referissem unicamente às experiências das mulheres brancas. No entanto, tal costume, praticado conscientemente ou não, perpetuou o racismo na negação da existência de mulheres não-brancas nas Américas (hooks, 1981, p. 9).

O feminismo negro defendia (e persiste defendendo) o enfoque nas diferenças de raça e classe ${ }^{8}$ que atravessam a subjetividade das mulheres. Lembra-nos Davis $(2016$, p. 17) que "as mulheres negras sempre trabalharam mais fora de casa do que suas irmãs brancas", mantendo ainda hoje um padrão que era verificado desde os primeiros anos da escravidão. Ora, essa sinalização conturba a clássica polaridade entre espaço público sob o domínio da presença masculina e espaço privado, com enclausuramento das mulheres, e requer uma nova visada sobre o adágio feminista "o privado é político". No que concerne à feminilização do magistério, a perspectiva do feminismo negro nos ajuda a romper com a noção de que o exercício do magistério, ainda que em condições de disparidade de gênero, ampliou a inserção das mulheres no espaço público do trabalho. Para as mulheres negras não se tratou de uma ampliação e nem reverberou em retração de sua presença majoritária no trabalho doméstico.

A lógica das restrições pode ser explicada pela inaplicabilidade às mulheres negras da ideologia da feminilidade erguida no século XIX. No contexto do sistema escravista mulheres negras (e nesse aspecto não se distinguiam dos homens negros) eram unidades de trabalho lucrativas, desprovidas de gênero. O papel de mães, protetoras, parceiras, donas de casa amáveis, não Ihes cabia. Como conclui Davis (2016, p. 18), as mulheres negras eram praticamente "anomalias" 9 .

Ainda hoje a representação predominante acerca da mulher negra está fortemente associada à lascividade e à servidão. Ao corpo da mulher negra não são atribuídas características femininas estereotipadas, como a delicadeza e a fragilidade. Atravessado pelo racismo e configurado em relações sociais racializadas desde o escravismo, o corpo da mulher negra é hiperssexualizado e apto aos diversos tipos de trabalhos não intelectualizados.

8 Kimberly Crenshaw (2002) formulou o conceito de interseccionalidade como ferramenta analítica para compreender as opressões sofridas em forma de violências a partir dos marcadores de raça, gênero e classe. Nesse artigo, optamos por nos apoiarmos nas feministas negras que inauguraram esse debate.

9 Sobre esse aspecto remetemos às analises de Angela Davis (2016) e de bell hooks (2018), ambas formulações originais de 1981 inspiradas no emblemático discurso proferido por Sojourner Truth na Convenção Nacional pelos Direitos das Mulheres em Akron, em 1851. 
Por conseguinte, a ideologia da feminilidade que relegou as mulheres brancas à profissão docente promoveu, em contrapartida, a restrição das mulheres negras nesse ambiente. Por isso, ao lado da inegável feminilização do magistério é forçoso considerar, a racialização da profissão, que pode ser comprovada desde as barreiras para que as mulheres negras atinjam níveis mais elevados de educação que thes faculte o ingresso em profissões intelectualizadas, até a presença relegada aos níveis mais desvalorizados da profissão - os anos iniciais da educação básica ${ }^{10}$.

Como escutamos de nossas entrevistadas, as mulheres negras que ingressam no magistério ainda estão "fora do lugar".

Eu já tive esse enfrentamento lá: “Nossa, essa negra estudou aqui nesta escola e voltou pra essa escola?" Por ser assim, negra, e por ter estudado naquele colégio [...] a minha formatura de magistério foi nessa escola. Hoje já tem o que? Três anos que eu trabalho lá nessa escola. Hoje eles já me olham com outro olhar, sabe? (Professora Rosária, Entrevista Narrativa, 2017).

Por meio da abordagem (auto)biográfica foi possível uma aproximação das vivências singulares de gênero e de raça que são sustentam as performances de ser professora quilombola. Um aspecto importante diz respeito a capacidade de ressignificar o status da profissão docente. Malgrado a precarização da docência, no contexto das negativas de direitos à população quilombola, exercer a carreira docente pode significar a mobilidade social que distancia essas mulheres da exploração do trabalho doméstico ou do trabalho na agricultura.

\section{Articulações da docência quilombola}

Claro a gente têm que saber das nossas raízes, da onde que a gente veio, porque é muito importante e todo mundo sabe que a base da vida da gente é a raiz. Porque a gente tem que saber realmente quem a gente é na realidade. (Entrevista narrativa, Professora Dermita, 2017).

Muitos elementos estão em jogo no complexo processo que conduz à elaboração de uma docência quilombola. Conforme observamos nas narrativas, a educação das relações étnico-raciais foi um tema ausente formação inicial das docentes, um assunto no qual "ninguém tocava". Como nos disse a professora Terezinha, Ninguém falava da questão de ser negro. Ninguém. Aquilo ali era muito distante de nós. Nós sendo negros, mas tudo distante. Quanto tempo a história ficou parada? Sendo que nós estávamos no contexto da história e não sabíamos!

A instauração de uma educação escolar quilombola converge com a articulação de práticas discursivas em muitos âmbitos sociais nos quais o conhecimento da história e da cultura africana e afro-brasileira são reportados, como é o caso das associações quilombolas. Nesse sentido, a participação das professoras entrevistadas em atividades políticas e formativas propostas, por exemplo, pela CONAQ e COQUIVALE11, tem se constituído em importantes espaços capazes de contribuir para a construção dessa pertença étnicoracial. Essa integração também se constituiu em um espaço de trocas de saberes a respeito das comunidades quilombolas no que se refere a suas necessidades e capacidade produtiva, sua dinâmica territorial específica e sua cultura.

10 Nesse artigo não apresentaremos dados quantitativos sobre a distribuição da frequencia das mulheres negras nos níveis ensino. Registramos, entretanto, que somente nas últimas décadas é possível observar essa presença no nível superior de ensino em condições não excepcionais, embora ainda bastante assimétricas em relação às mulheres brancas.

11 Comissão das Comunidades Quilombolas do Vale do Jequitinhonha. 


\section{autêntica}

Também é notável nas narrativas que as professoras passaram a investir na participação na dinâmica interna do quilombo com vistas ao acesso a direitos.

[...] Sabíamos que éramos quilombolas, a comunidade foi reconhecida como quilombola, mas não teve ninguém para chegar até à comunidade e explicar que alguém iniciou o processo de dentro da comunidade, através do Decreto 4887/2003 que garante o território, a delimitação do territorial para a comunidade. [...] Eles só vieram a ter essa clareza quando chegou o grupo de antropólogos pra fazer o Laudo Antropológico e pediram a Certificação. Aí o que eu fiz? Eu comecei a pesquisar. Eu perguntava qual é a lei? Eles falavam do decreto 4.887, do decreto 6.040 de povos e comunidade tradicionais [...] Tudo o que eles iam me falando, ia pesquisando para ir informando, a toda a comunidade e as pessoas que também me perguntavam. (Professora Sirlene, entrevista narrativa, 2017).

De acordo com a narrativa, outros conhecimentos passam a fazer parte do repertório dessas professoras, assim como ocorre também uma proeminência de sua presença para a comunidade. Falando desde dentro - "sabíamos que éramos quilombolas" - a professora faz convergir sua experiência militante e docente e produz uma reinstauração do status social dessa docência. E a partir dessa posição também vocaliza demandas fora do quilombo. A narrativa de Sirlene demonstra seu questionamento à educação que ocorria na escola em que ela atuava, fora do quilombo.

Uma educação assim! Tá bonita de ler nas diretrizes, nem no PPP não tem nada voltado [...] uma Educação Escolar Quilombola, não tem. Se você vai discutir, conversar com coordenadoras da escola, elas não trabalham, porque não está no PPP da escola. Só fazem o que a secretaria municipal manda e quer né! Eu uma vez cheguei a recusar a entregar uma folha com um negro dependurado em um pau com algemas, era para as crianças pintarem. É assim que a escola trabalha? Sem nenhuma informação, sem nenhuma história? E como é que essa criança vai olhar para esse desenho e ver alguma representatividade naquele papel, onde o negro está lá amarrado com uns ferimentos nas costas. E outra coisa assim "e tia que cor que eu pinto?". (Professora Sirlene, Entrevista Narrativa, 2017).

A recusa de Sirlene indica tensões desconsideradas nos cursos de formação inicial, ou só muito recentemente acessadas. A professora não mobilizou o repertório de sua formação inicial nesse episódio e nem contou com referências do projeto político pedagógico da própria escola para combater a naturalização da violência e desumanização dos corpos negros.

As narrativas também nos levam a perceber que a experiência dessa docência quilombola é tão múltipla e variada quanto a diversidade dos territórios quilombolas. Terezinha elabora a docência em uma escola que é considerada como um lugar da comunidade. Em suas palavras, "tudo acontece na escola. É tudo. Dia de apresentações é portão aberto para o povo participar. É uma coisa muito boa, é um aconchego. Não tem essa coisa de separar a escola de comunidade" (Professora Terezinha, Entrevista Narrativa, 2017). Conforme observamos, o engajamento na dinâmica do quilombo é comum, seja no Norte de Minas, como no caso de Sirlene e Dermita, seja no Vale do Jequitinhonha, como expressa Terezinha:

E estou na luta trabalhando. Ajudando o quilombo a crescer com muita satisfação, porque é gratificante a gente poder olhar para meninos, e depois eles falarem o quanto foi importante o trabalho que nós fizemos com eles. E o quanto eles cresceram. Os vendo com autoestima nesta questão, na luta. Eles aprendem a lutar também [...] E tudo que a comunidade faz a escola tem que estar. (Professora Terezinha, Entrevista Narrativa, 2017). (Grifos nossos).

Ao dizermos de aspectos em comum, não estamos sugerindo uma linha de continuidade na comparação entre as experiências. Em nossa perspectiva, trata-se de elementos em confluência quando se coloca em 


\title{
autêntica
}

DOI https://doi.org/10.31639/rbpfp.v12i24.348

questão o direito ao reconhecimento quilombola, que é articulado pela "presunção de ancestralidade negra" (Brasil, 2003). Nesse diapasão, a ancestralidade negra veio a compor a prática discursiva das associações comunitárias e entrou em disputa nas escolas, atravessando conteúdos e práticas curriculares.

Nas narrativas das professoras quilombolas, a corporeidade negra manifesta-se por meio do corpo e do cabelo e se constitui como um dos principais marcadores de identificação racial. Geralmente, a identificação desses marcadores ocorre por meio de estigmas que promovem a desumanização, seja pela ofensa racista, seja pela exigência de táticas de branqueamento, como o alisamento capilar. Como nos lembra Gomes (GOMES, 2008, p. 247), identificar o cabelo do negro como "ruim" e do branco como "bom" expressa um conflito. Por isso, mudar o cabelo pode representar um sentimento de autonomia, expresso nas formas ousadas e criativas de usar o cabelo".

Ao adotarem uma posição afirmativa em relação ao corpo negro e cabelo crespo as professoras mobilizam o modo como estudantes quilombolas lidam com seus próprios corpos negros e cabelos crespos.

[o uso do cabelo crespo] É tudo muito espontâneo. Tudo com muita segurança. Ninguém faz nada assim, aquela coisa só de fachada é tudo muito verdadeiro. E as meninas aceitam o cabelo de verdade. Mudou! Ninguém mais quer usar hoje [cabelos alisados]. E assim elas falam como se sentem bem. Assim usando o cabelo natural [crespo] na escola. (Professora Terezinha, Entrevista Narrativa, 2017).

Em outro caso, a professora promoveu deliberadamente uma ação pedagógica em articulação com a comunidade:

\begin{abstract}
Então eu fiz uma proposta para nós fazermos um produto na comunidade de Puris, trabalhar e como já estávamos quase no final do ano a gente poderia trabalhar o dia da Consciência Negra. [...] E fiz a proposta de fazermos um desfile dentro da comunidade, [...] a gente juntou os tecidos, e fiz aqui na minha cabeça, estava tudo montando como eu iria fazer. Compramos os tecidos de chita, e fizemos as roupas no corpo dessas meninas e chamei uma amiga, que fez a maquiagem nas meninas, e tivemos a ajuda da comunidade, chamei toda a comunidade para prestigiar. A gente fez um desfile. Em primeira mão as meninas não queriam participar, porque o desfile dá aquela ênfase que é uma disputa de beleza. Então, tem essa característica que é para ver quem é mais bonita. E aí eu pensei comigo que não era para ter isso o que íamos fazer era um desfile para valorizar a beleza que cada um essas meninas traziam, sabe? Cada traço, cada raiz familiar que elas traziam. Aí eu expliquei para elas que não teria disputa, quem era a mais bonita, a menos bonita. Então elas concordaram. É foi assim o dia marcado para acontecer esse evento, foi um dia a tarde na escola, conversei com a coordenadora [...] ficou tudo concentrado para esse evento, a comunidade toda participou. (Professora Sirlene, Entrevista Narrativa, 2017).
\end{abstract}

Esse desfile de beleza negra é uma estratégia pedagógica consoante a muitas escolas, e não somente quilombolas. No caso em tela, passou a compor a programação anual do Dia da Consciência Negra, em 20 de novembro, com o objetivo de valorização e fortalecimento da identidade quilombola. Em outras edições contou com a participação de mulheres adultas e idosas da comunidade. A partir dessa iniciativa, Sirlene intensificou o trabalho com a confecção de vestuário utilizando tecidos com estampas étnicas africanas e atualmente produz grife de roupas Negra Arte. Sirlene nos contou que "nos desfiles realizados com as jovens da minha comunidade eu queria fazer algo que retratasse e afirmasse a identidade da mulher quilombola, acredito estar no caminho certo." Assim, a sua produção em moldes na economia solidária foi direcionada para atender a demanda da população negra, especialmente, as mulheres desapocadas ${ }^{12}$ que buscam produtos específicos, os quais trazem os elementos étnicos relacionados à cultura afro-brasileira. Na relação gênero, raça e classe a atuação dessa docente extrapola a escola.

12 De acordo com Passold (2017, p. 101) o termo dasapocada é uma "categoria nativa" dos Puris e pode ser compreendida como "uma forma de fazer frente às opressões vividas por todas nós, mulheres negras em todo o país.” Assim para além da beleza a mulher desapocada é aquela que reúne uma série de característịcạs (desinibida, proạtivạ, eduçadạ, etce.). 


\section{autêntica}

Dol https://doi.org/10.31639/rbpfp.v12i24.348

\section{Considerações finais}

Conforme nos deram a conhecer as entrevistadas, a docência quilombola que constroem está atravessada pelos dilemas da identidade racial. Nesse sentido, desarticulam a perspectiva eurocêntrica da estética branca e explicitam as violências do racismo. Nessa ação sustentam uma performance em que se afirmam mulheres negras.

Outro aspecto dessa docência quilombola é sua inscrição no território quilombola. A participação militante em redes de troca em que acessam outros quilombos amplia o leque de conhecimentos que passam a compor o repertório dessas professoras. O acesso a informações sobre direitos específicos da população quilombola permite-Ihes assumir um lugar proativo na dinâmica interna do quilombo. Em suma, a docência quilombola ocorre nas fronteiras do quilombo e do gênero. 


\section{autêntica}

DOI https://doi.org/10.31639/rbpfp.v12i24.348

\section{Referências}

APPLE, Michael W. Trabalho docente e textos: economia política das relações de classe e de gênero em Educação. Porto Alegre: Artes Médicas, 1995.

ARAÚJO, Helena Costa. As mulheres professoras e o ensino estatal. Revista Crítica de Ciências Sociais, n. 29, p. 81-103, 1990.

ARRUTI, José Maurício. Mocambo: antropologia e história do processo de formação quilombola. Bauru, SP: EDUSC; São Paulo Associação Nacional de Pós-graduação e Pesquisa em Ciências Sociais. 2005. 368p.

ARRUTI, José Maurício. Quilombos. In: PINHO, Osmundo (Org.). Raça: novas perspectivas antropológicas. Salvador: ABA / Ed. Unicamp / EDUFBA, 2008.

Brasil. Conselho Nacional de Educação/Câmara de Educação Básica. Resolução n. 8, de novembro de 2012. Diário Oficial da União. Brasília, DF, 21 nov. 2012.

Brasil. Decreto $n^{\circ}$ 4.887, de 20 de novembro de 2003. Brasília (DF). Disponível em: http://www.INCRA.gov. br/portal/.../legislacao_quilombola_condensada.pdf . Acesso em: 22 jan. 2018.

Brasil. Instituto Nacional de Colonização e Reforma Agrária. Cartilha de Regularização de Território Quilombola Perguntas \& Respostas. Disponível em: http://www.incra.gov.br/sites/default/files/incra-perguntasrespostas-a4.pdf

Brasil. Secretaria de Políticas de Promoção da Igualdade Racial - Seppir. Guia de Políticas Públicas para Comunidades Quilombolas. Programa Brasil Quilombola. Brasília, DF, 2013. 61 p. Disponível em: www. palmares.gov.br/.../ANEXO-04-Portaria-FCP-n98-de-26-de-novembro-de-2000. Acesso: 06 de set. 2017.

Brasil. Secretaria de Políticas de Promoção da Igualdade Racial. Programa Brasil Quilombola. Brasília, 2015. Disponível em: <http://www.seppir.gov.br/portal-antigo/.arquivos/relatorio-pbq-2012> Acesso em: 10 de ago. 2017.

CARVALHO, Maria Celina Manzoli, SCHMITT, Alessandra, TURATTI, Maria Cecília M. A Atualização do Conceito de Quilombo: identidade e território nas definições teóricas. Ambiente \& Sociedade. Campinas: SP, ano V, $\mathrm{n}^{\circ} .10,1^{\circ}$ sem. 2002.

CHAMON, Magda. Relações de gênero e a trajetória de feminização do magistério em Minas Gerais (18301930). Belo Horizonte - MG. 1996. (Tese de Doutorado).

CRENSHAW, Kimberlé. Documento para o encontro de especialistas em aspectos da discriminação racial relativos ao gênero. Estudos Feministas. Florianópolis: Centro de Filosofia e Ciências Humanas, v.7, n.12, 2002, p. 171-188.

DAVIS, Angela. Mulheres, raça e classe. Tradução Heci Regina Candiani. 1. Ed. São Paulo: Boi Tempo, 2016.

FARIAS, Luciano Mendes de Filho. Instrução elementar no século XIX. LOPES, Eliane Marta Teixeira; FARIA, Luciano Mendes de Filho; VEIGA, Cynthia Greive. (Org.). In: 500 anos de educação no Brasil. Belo Horizonte: Autêntica, 2011, 307-326. 


\section{autêntica}

DOI https://doi.org/10.31639/rbpfp.v12i24.348

HAHNER, June E. Escolas mistas, escolas normais: a coeducação e a feminização do magistério no século 19. Estudos Feministas, Florianópolis, v. 19, n. 2, 2011, p. 467-474.

HALL, Stuart. A identidade cultural na pós-modernidade. TraduçãoTomazTadeu da Silva, Guacira Lopes Louro - 11ed. Rio de Janeiro DP\&A, 2006.

GOMES, Nilma Lino. A mulher negra que vi de perto. 2ª Ed. Belo Horizonte: MAZZA Edições. 1995.198 p.

GOMES, Nilma Lino. Educação, raça e gênero: relações emersas na alteridade. Cadernos Pagu - raça e gênero, n. 6-7, Núcleo de Estudos de Gênero da UNICAMP, Campinas: SP, 1996, p. 67-82.

GOMES, Nilma Lino. Sem perder a raiz: corpo e cabelo como símbolo da identidade negra. $2^{a}$ ed. Belo Horizonte: Autêntica, 2008.

GOMES, Nilma Lino. As práticas pedagógicas com as relações étnico-raciais nas escolas públicas: desafios e perspectivas. In: GOMES, Nilma Lino (Org.). Práticas pedagógicas de trabalho com relações étnico-raciais na escola na perspectiva da Lei no 10.639/03. Ed. Brasília: MEC; Unesco, (Educação para todos; 36), 2012, p. 19-34.

Minas Gerais. Secretaria de Estado da Educação. Diagnóstico Institucional da Educação Escolar Quilombola. 2015.

MULLER, Maria Lúcia Rodrigues e PAIXÃO, Lea Pinheiro. Educação, Diferenças e Desigualdades. Editora: Edufmt, 2006.

MÜLLER, Maria Lúcia Rodrigues. A produção de sentidos sobre as mulheres negras e o branqueamento do magistério no Rio de Janeiro na Primeira República. FONSECA, M. V.; BARROS, S. A. P. (org.). A História da Educação dos Negros no Brasil. Niterói: EdUFF, 2016

MIRANDA, Shirley Aparecida. Educação Escolar Quilombola em Minas Gerais: entre as ausências e emergências. Revista Brasileira de Educação. Rio de Janeiro, ANPED, v. 17, n 50, p. 369-384. mai./ago., 2012.

MIRANDA, Shirley Aparecida. Quilombos e educação: identidades em disputa. Revista EDUCAR. Paraná, V. 34, n 69, p. 369-384. mai./jun., 2018. Disponível em: https://revistas.ufpr.br/educar/index. Acesso em: 13 de jun. 2018.

MOURA, Clovis. Rebeliões da senzala: quilombos, insurreições, guerrilhas. 3. ed. São Paulo: Livraria Ed. Ciências Humanas, 1981.

NÓvOA, António. Os professores: Quem são? Donde vêm? Para onde vão? Lisboa: ISEF, 1989.

SANTANA, Patrícia Maria de Souza. Modos de Ser Criança no Quilombo Mato do Tição - Jaboticatubas Minas Gerais. (Tese de Doutorado). Programa de Pós-Graduação em Educação. Universidade Federal de Minas Gerais, Belo Horizonte, 2015. 


\section{autêntica}

DOI https://doi.org/10.31639/rbpfp.v12i24.348

SÁ, Carolina Mafra de; ROSA, Walquíria Miranda. História da feminização do magistério no Brasil: uma revisão bibliografia. CONGRESSO BRASILEIRO DE HISTÓRIA DA EDUCAÇÃO, 3, 2004. Anais ... Curitiba: PUC-PR, 2004.

SILVA, Jairza Fernades Rocha. Deslocamentos identitários de gênero e raça de professoras negras na educação escolar quilombola em Minas Gerais. (Dissertação de Mestrado). Programa de Pós-Graduação em Educação. Universidade Federal de Minas Gerais, Belo Horizonte, 2018.

MIRANDA, S. A.; SILVA, J. F. R.; Docência nas fronteiras: quilombo, raça e gênero . Formação Docente - Revista Brasileira de Pesquisa sobre Formação de Professores. Belo Horizonte. Vol. 12, no 24 (p. 39-52) 31 ago. 2020 